\title{
LOS VENENOS DE BAROJA
} Aslan Cohen*

RESUMEN: La relación de Pío Baroja con los venenos llegó a ser profunda; el suicidio de su personaje en El árbol de la ciencia será culminación de su pensamiento sobre los fluidos materiales, como el sabor del fruto prohibido que trajo la muerte al mundo: toda la vida un a pesar de la muerte.

PALABRAS CLAVE: Baroja, El árbol de la vida, antivitalismo, veneno, muerte.
ABSTRACT: The acquaintance of Pío Baroja with poisons was indeed deep. The suicide of his character in the Tree of Knowledge would be the apex of his ideas regarding material fluids, as the taste of the forbidden fruit that brought death to the world: all life occurs despite death.

KEYwORDS: Baroja, The Tree Of Life, anti-vitality, poison, death.
RECEPCIÓN: 14 de mayo de 2013.

ACEPTACIÓN: 14 de noviembre de 2013.
* Economista por el ITAM. Estudiante de filosofía en la UNAM. 


\section{LOS VENENOS DE BAROJA}

...for who can speak of Eternity without a solocism, or think thereof without an Extasie?

Sir Thomas Browne*

Obnubilado, esperando como parásito las palabras, me siento a escribir sobre Baroja. Frente a mí están abiertos su novela El árbol de la ciencia y mi cuaderno con notas sobre ella; más lejos, cerrado, el noveno tomo de las Obras completas de Ortega, donde he leído las páginas venerables sobre el vasco: Pí Baroja: anatomía de un alma dispersa. Un aforismo de Kafka, escrito en enero de 1918 -cuando Kafka pensó mucho sobre la expulsión del Paraíso-, gira alrededor de mis ideas vaporosas con tediosa gravedad, y es apenas lo único planetario en mi nebuloso estupor. Vacilo. En fin, las notas que he

* Sir Thomas Browne, Religio Medici, 1909, Nueva York, The Harvard Classics, ed. by Charles W. Eliot, p. 274. hecho me han resultado chocantes y más me vale empezar por algo.

No sólo estamos en pecado por haber comido del árbol del conocimiento, sino también por no haber comido aún del árbol de la vida. Nuestro ostracismo, justificado tradicionalmente por una acción, se debe también a una omisión. La condena humana supone haber comido del fruto de la ciencia, sí; pero también el haber ignorado el vástago de la vida. Enigmática abstención, porque el inmortal no se abstiene: aplaza. En ningún lugar se nos dio a elegir entre un árbol y otro; sólo uno estaba proscrito. ¿Por qué no, entonces, comer antes del árbol de la vida, si teníamos la eternidad? Pero el hombre, ya desde entonces un tanto heteróclito y bifur- 
cado, valora, excluye, decide. Es como si ya en su andar hacia el árbol del conocimiento se fuera haciendo consciente; y ya en el jardín de su inmortalidad aprendiera a ser mortal.

Atendiendo a su contenido moral, lo que extraemos de esta sentencia kafkaiana es que una misma consecuencia (el pecado) se encuentra doblemente determinada por un hacer y por un no-haber-hecho; cosa, por lo demás, bastante común para nosotros. Padecer una existencia finita significa que al elegir debemos rechazar. Los mortales debemos responder por lo que decimos y por aquello que, al decir, callamos. Lo desconcertante de la afirmación radica en que, para Kafka, dicha condición se remonte al estado paradisíaco. Aún no éramos mortales, nos dice, y ya éramos libres. Parece una paradoja imposible: la deliberación de la voluntad sólo puede entenderse si está circunscrita a la temporalidad, pues así como el espacio tensa las cosas hasta fisurarlas en contornos que nos entregan formas, así el tiempo aturde al tallo de la voluntad en una fugaz explosión de brotes imaginados, hasta que, con el acto, ella, madurando en la única flor a la que cede el duro instante, nos cristaliza el rostro en esta mirada.

Pero Kafka ve más lejos; para él, la condición de posibilidad de la libertad humana no es el tiempo, sino que el tiempo es engendrado necesariamente de una condición humana que no puede entenderse sin la libertad. El hombre y la libertad nacen simultáneamente en el momento de rebelión en contra de lo eterno y del Eterno; es, por lo tanto, una rebelión anárquica en su sentido etimológico, pues ocurre más allá del principio del tiempo que engendra, y más allá del principio de autoridad que niega. Con esto, el acto de afirmación de la libertad humana es la utopía del tiempo, su no-lugar, pues aún no se encuentra en la finitud, pero ya no sucede en la eternidad.

La eternidad, por otra parte, está hecha de una materia que no admite proyecto. Una línea antes del aforismo que hemos comentado, en la misma página del diario, Kafka condensa preciosamente esta idea. El lamento: cuando yo sea eterno, ¿cómo seré mañana? Verdaderamente, esta pregunta debió estar siempre en fondo del corazón del hombre, cohabitando con el terror punzante de la muerte, en cuyos ojos hemos creído encontrar la imposibilidad radical de volvernos a hacer. Y qué, sino la negativa a renunciar a esta pregunta dispuso las doctrinas de los hinduistas, quienes supusieron pacientemente una cadena indefinida de esta y otras vidas, aunque no menos empeñosamente que los pitagóricos, para quienes los eslabones de esa cadena son cuerpos variables que el alma penetra, sin alcanzar nunca la estación definitiva. De todo ello, se sigue que los 
hombres queremos retener no este o aquel objeto, sino la posibilidad misma de seguir queriendo; y aun si no bastaran esos ejemplos para probarlo, Estrabón, en el libro XV de su Geografia, hablando de las regiones orientales que están después del río Hipanis, dice que por ignorancia, o debido a su remota situación, todo lo narrado acerca de esas lejanas tierras deviene hipérbole, o al menos colinda con la fantasía, como lo prueban historias de hormigas escarbadoras de oro, ${ }^{1}$ y relatos de hombres y bestias de extraña figura que, gracias a ciertos poderes, adquirieron extraordinarias facultades, como los habitantes de Scitia, cuyas vidas alcanzaban a durar más de doscientos años: pero cómo podría soportarse una tal longevidad sin secarse el ánimo de la vida, no podemos saberlo; aunque es posible que, al haber sido Scitia el lugar originario de la seda, donde por generaciones enteras se observó y cultivó al gusano de seda, sus longevas gentes hayan logrado emular, en su anhelo transubstancial, el misterioso mecanismo por el que este animal teje a un tiempo el sepulcro en que se da a una muerte instantánea y el

${ }^{1}$ Dice Covarrubias s.v. 'hormiga' que "en la Etiopía Occidental se crían hormigas tan grandes como un gran perro; con los pies sacan las arenas de oro y persiguen hasta la muerte al que intenta robar su tesoro, y bien se verifica lo que dice Plinio, que la hormiga es animal sólo provechoso para sí", Sebastián de Covarrubias, Tesoro de la lengua castellana o española, 2003, Barcelona, Alta Fulla, ed. de Martín de Riquer, p. 700. suave vientre de donde saldrá a una vida nueva, encontrándolo como una magnífica alegoría del instante: angosto capullo en que se hiela la máscara del que fuimos e irrumpe la polifónica promesa de la siguiente mirada. Mas, a diferencia del precioso Bombyx mori, capullo tras capullo, nosotros escapamos inútilmente de un cuerpo que nos resiste y que va languideciendo con cada oscilación del espíritu, hasta que regresa vulnerado a la tierra y allí concluye, engendrando de su carne putrefacta, gusanos y pudrición. ${ }^{2}$

A menos que otros símbolos nos den la vida eterna. No la seda, sino la roca, cuyo imperturbable estatismo es reflejo de la inmortalidad, que otros han querido ver en el despreocupado pájaro que espulga su plumaje, en el perro que descansa indiferente, en el pez ingenuo. ${ }^{3}$ La eternidad podría estar entre nosotros, en la inconsciencia toda del mundo natural, de la que Borges deriva su insigne conclusión: ser inmortal es baladi; menos el hombre, todas las criaturas lo son, pues ignoran la muerte. ${ }^{4} \mathrm{Y}$ es que, aunque fuera duradera, aquella permanencia es una eternidad baldía, de lo cual es emblema el laurel infecundo en que fue tornada Dafne; sus tiernos miembros, de los que habló

${ }^{2}$ Ibid., p. 671.

${ }^{3}$ Charles Wright, Black Zodiak, 2002, Valencia, Pre-Textos, pp. 62-3.

${ }^{4}$ Jorge Luis Borges, "El inmortal" en El Aleph, 2004, Madrid, Alianza, p. 23. 
Garcilaso, ${ }^{5}$ para siempre petrificados, e impedidos para amar, no sólo a Apolo. Y me remito a Ovidio, quien parece estar observando cómo la corteza va envolviéndole a la ninfa los senos delicados, cómo sus cabellos verdean, alargándose en follaje, igual que sus manos en ramas, mientras que los pies ligeros son raptados por el letargo vegetal con el que los absuelve finalmente la humedad de la tierra; mas cómo la sangre de la dríade o ninfa de los árboles fue transmutándose en savia, lo calla. Debió espesarse y volverse cetrina, formando los coágulos viscosos que avanzan a borbotones por las paredes interiores de los tallos, lo cual sucedería luego de haberse acumulado un exceso de sangre en algunas partes de su cuerpo, sufriendo eso que los médicos llaman hiperemia, padecimiento que, por otra parte, sobreviene notoriamente al contacto con un fármaco extraído del perenne acónito, que al entrar en contacto con el torrente circulatorio produce uno de los más curiosos envenenamientos de que se tenga noticia, y que recuerda misteriosamente la trasformación de Dafne, no sólo porque "obtunde" la sensibilidad cutánea, sino porque produce una sensación de aspereza que se extiende desde la boca hasta el estómago, disminuye la temperatura y apaga la

${ }^{5}$ Garcilaso de la Vega, Obra poética y textos en prosa, 2007, Barcelona, Crítica, ed. de Bienvenido Moros, pp. 100-1. voz, desacelera la respiración y el pulso, y, al intoxicar los músculos, ocurre primero que se va haciendo difícil la marcha, hasta dejarlos paralizados en un espasmo que concluye con la suspensión en diástole de los latidos cardíacos. ${ }^{6}$

Además de esta descripción fisiológica, que reproduzco sólo fragmentariamente del Tratatado de terapéutica de un Josep Antoni Massó i Llorens, leo que fue Brandes quien, en 1819, descubrió en la raíz del aconitum una sustancia llamada aconitina, de la cual, nos dice, el comercio de su tiempo admitía las variantes de Morson y Hottot, fármacos ambos amorfos, incoloros e incristalizables. Sin embargo, escribe Massó, hasta 1870 Duquesnel obtuvo la aconitina pura, cristalizable en prismas y casi completamente insoluble en agua, pero soluble en benzina, éter, glicerina, cloroformo y alcohol; sería éste lo que probablemente había en la copa que, en la novela de Baroja, el tío Iturrioz encuentra al lado de un frasco con veneno de Duquesnel y del cuerpo intoxicado de su sobrino Andrés Hurtado; suscitando, a su vez, la especulación no infundada de que acaso Baroja haya escuchado por primera vez sobre este tipo específico de aconitina en la facultad de medicina de la Universidad de Valencia, donde

${ }^{6}$ Josep Antoni Massó i Llorens, Tratado de terapéutica, 1876, Establ. tip. de Narciso Ramirez, pp. 552-3. 
estudiaba en 1891, y donde, a comienzos de ese mismo año, Massó i Llorens impartía cursos sobre "terapéutica y materia médica".?

Como quiera que sea, la relación de Baroja y los venenos se volvió profunda, y el suicidio de su personaje será la culminación de una larga meditación sobre los fluidos materiales que se intercambian en los ciclos vitales de la Tierra. Agua o savia, o sangre o miel o miasma: para $\mathrm{Ba}-$ roja todo es veneno. Todo lo natural se reduce a la sustancia que las cosas inyectan o succionan a las cosas para satisfacer el impulso mezquino de la vida. La hiena que monda los huesos de un cadáver, nos dice Baroja, la araña que sorbe una mosca, no hace ni más ni menos que el árbol bondadoso llevándose de la tierra el agua

${ }^{7}$ De haber ocurrido directamente -porque Baroja pudo haber escuchado sobre el trabajo del catalán también a través de sus compañeros-, el encuentro de Baroja con Llorens sucedió entre enero y febrero de 1891. Pese a que nuestro autor estudió casi toda la licenciatura en medicina en Madrid, a comienzos de ese año el trabajo de su padre le obliga a mudarse a Valencia, y allí obtiene el título. Paralelamente, Massó y Llorens, quien en 1888 enseñaba en Granada, obtiene el traslado a la universidad valenciana en 1889 , institución que deja en febrero de 1891 para irse a Barcelona. Sobre este particular dato biográfico de Baroja, véase: Pío Caro Baroja, "Un Baroja extravagante" [en línea]. El correo digital. <http://info.elcorreo. com/territorios/articulo/literatura/ 1002394/unbarojaextravagante.html >. Consulta: [24 de mayo, 2012]. Para una biografía comprensiva de Massó y Llorens: J. L. Austín Hervella y J. M. Calbet Camarasa, "Notícia biogràfica del metge Josep Antoni Massó Llorens", Gimbernat, núm. 42, 2004, pp. 167-81. y las sales necesarias para su vida. ${ }^{8}$ Ni siquiera el hombre escapa a este estado lacerante de usurpaciones continuas, porque está inscrito en los modos funcionales de lo orgánico: y llevando este determinismo al extremo de la simplificación, Baroja sugiere una especie de entomología humana que reconocerá cada tipo psicológico en el mecanismo insecto, o de cualquier otra entidad diminuta -el microbio, el hongo.

Ese usurero [...] iqué de avatares no tiene en la zoología! Ahí están los acinétidos chupadores que absorben la sustancia protoplasmática de otros infusorios; ahí están todas las especies de aspergilos que viven sobre las sustancias en descomposición. Estas antipatías de gente maleante, ¿no están admirablemente representadas en ese antagonismo irreductible del bacilo de pus azul con la bacteridia carbuncosa?

Así sigue Baroja a lo largo de una página, acosándonos con ejemplos de brutalidad minuciosa; lanzándolos a nuestra cara con esa agresividad de la que está plagada su escritura: Ahí tienes el ichneumon... ahí están las avispas... ahí está el estafilino... ahí está el meloe... ${ }^{9}$ Como si nos dijera: ahí está el ladrón, el adulador, el

${ }^{8}$ Pío Baroja, El árbol de la ciencia, 2008, Barcelona, Caro Raggio/Cátedra, p. 26.

${ }^{9}$ Ibid., p. 129. 
traicionero, el oportunista, el mendigo, el parásito. Toda la escoria humana es localizable en la más diminuta entidad natural, y es que, como dice Iturrioz, todo lo natural, todo lo espontáneo es malo; sólo lo artifical salva. ${ }^{10}$ Parco formulismo de maniqueo dogmático que pretende resolver la existencia del hombre con una ecuación aplicable al escarabajo. Y llamo a Baroja maniqueo en el sentido original, porque como maniqueo cree en la realidad material del mal, en que sus partículas andan dispersas por todo aquello que está corrompido. Basta un párrafo para demostrarlo: esta vez es Hurtado mismo quien afirma que la situación de miseria de las mujeres del burdel se debe a:

lo que queda de moro y de judío en el español; el considerar a la mujer como una presa, la tendencia al engaño, a la mentira... Es la consecuencia de la impostura semítica; tenemos la religión semítica, tenemos sangre semita. De este fermento malsano, complicado con nuestra pobreza, nuestra ignorancia y nuestra vanidad, vienen todos los males.

Este racismo no puede tomarnos por sorpresa, pues es sólo el paso siguiente de las doctrinas que, a fuerza de una antropología inverosímil y torcida, pretenden anular la libertad para expiar las culpas propias. Y en

${ }^{10}$ Ibidem . esto no difiere el aserto de Andrés Hurtado del desvarío fascista de un Alfred Rosenberg, o de las elucubraciones de la criminología de un Cesare Lombroso, quienes se empeñaron en reducir las dimensiones anímicas a las delineaciones del cráneo. En efecto, como dice Ortega, esa concepción de Baroja del pueblo como anatomía está en línea con un determinismo materialista tan ridículo como el que se lee en el libro de Hammon, y que afirma "que el cráneo del homo alpinus, es decir, del honrado suizo, produce una enorme capacidad tributaria y una gran afición a montar en bicicleta". ${ }^{11}$ Esta digresión podría fácilmente desviar nuestra atención hacia las ideas políticas del propio Baroja; pero, como aquí nos ocuparemos de su escritura, dejemos eso ahí y consideremos, hablando de cráneos y humores, el curioso mote con el que Hipócrates designaba el cerebro: metrópolis de la humedad. ${ }^{12}$

La medicina hipocrática veía en el cuerpo humano una composición de cuatro sustancias: la sangre, la bilis, la melancolía y la flema. El estómago, al recibir los alimentos que la boca ingiere, se vuelve una fuente

${ }^{11}$ José Ortega y Gasset, “Anatomía de un alma perdida" en Obras Completas, 1989, Madrid, Alianza, vol. 9, p. 487.

${ }^{12}$ Apud Sir Thomas Browne, "Hydriotaphia: Urn Burial”, Sir Thomas Browne's Works, 1835, London, Josiah Fletcher, vol. III, ed. by Simon Wilkin, p. 477. 
de calor que al contacto con los cuatro humores, hace que éstos vayan evaporándose y alcancen así el cerebro. ${ }^{13}$ Estos néctares han viajado por los sentidos interiores y han recogido ahí las sensaciones exteriores que los primeros asimilaron; y ahora, sublimados y congregados en el cerebro, traducen en imágenes las sensaciones aprehendidas, que muestran luego al alma para que ésta las considere, las piense y las contemple. ${ }^{14}$ Ahora, es cierto, nuestra medicina moderna niega estos procederes; mas pruébese científicamente todo lo que se quiera, y aún nuestros pensamientos seguirán siendo las intangibles y vaporosas entidades donde se lee el mensaje ascendente de nuestras células. La pervivencia milenaria de la doctrina de los humores se explica por la verdad fundamental de la que partía en sus especulaciones: la experiencia mental es inconcebible por sí sola: ella depende en gran medida de una sensación general de nuestro cuerpo. La imaginación, la razón, el juicio son aconteceres emotivos, anímicos, vitales. Un pensamiento puede ser melancólico, y esa es la prueba.

${ }^{13}$ El estómago, dice Sor Juana, "templada hoguera del calor humano, / al cerebro envïaba / húmedos, más tan claros los vapores / de los atemperados cuatro humores", Sor Juana Inés de la Cruz, "El sueño" en Obras Completas de Sor Juana Inés de la Cruz: vol. I, Lírica personal, 2004, México, FCE, ed. de Alfonso Méndez Plancarte, vv. 253-6.

${ }^{14}$ Octavio Paz, Sor Juana Inés de la Cruz o las trampas de la fe, 2010, México, FCE, p. 488.
Es la higiénica pretensión de Baroja querer negar esta verdad y disociar así al conocimiento de la vida. Mientras lo que sepamos no se parezca a las verdades matemáticas, hay que abstenerse de vivir, de afirmar; debemos esperar hasta que la Ciencia, fuerza impersonal, dicte. ${ }^{15}$ Las ideas, entonces, se dibujan para el vasco como absolutamente exteriores y artificiales; ellas no provienen del alma, sino que se limitan a ser despersonalizadas entidades incompatibles con lo orgánico, de modo que quien busca la verdad la busca no sólo a pesar de la vida, sino en contra de ella. De ahí le viene la heroicidad a Andrés Hurtado: del sacrificio de su vida en nombre de la verdad muerta que defiende; y hasta tal punto llega esto a fraguar en la totalidad de la novela, que ese profundo antivitalismo no deja de exponérsenos: tanto en la forma conceptualista de su adusta, parca, lacónica, prosa, como en su contenido esquemático, frío, confuso. Porque aunque a Baroja le aqueja el prurito de llamar a las cosas por su nombre, no suele ser claro. ${ }^{16} \mathrm{Y}$ si la escritura es, en sí misma, una realidad presencial, hierba separadamente escrita, entonces el libro de Baroja es un páramo chamuscado, dominado por el insecto y por la hiena. Mas un páramo que no es paisaje, que no logra siquiera comunicarnos el senti-

\footnotetext{
${ }^{15}$ Baroja, op. cit., p. 172.

${ }^{16}$ Ortega, op . cit., p. 479.
} 
miento de la sed, de la amargura. Sí, El árbol de la ciencia no es ni siquiera una novela amarga, porque su narrador y su protagonista odian el sabor de la literatura; la precisión científica de las palabras de Baroja declaran, a cada paso, un funesto anatema a la poesía. Excomulgar a la poesía de una obra literaria es condenarla al fracaso, porque es arrebatarle la sustancia de vida al mundo que se pretende fundar: en palabras de Ortega, significa fracasar en la creación de un "ambiente espiritual", en la "aspiración esencial del arte novelesco: suscitar en torno a unas figuras el medio de que espiritualmente viven, en que se personalizan". ${ }^{17}$

Pero este fracaso, creo, no se debe a la ineptitud de Baroja, sino a una convicción; cada vez que se acerca a lo literario y está a punto de transmitirnos esa indecible materia que permite que nos identifiquemos con los personajes, se detiene; y aunque a ratos quisiéramos que Baroja "nos trajera saltando por lo conceptual más cerca de la sensibilidad", ${ }^{18}$ se limita a las fórmulas filosóficas, a los dictámenes opacos. Se limita, por ejemplo, a decirnos que la muerte de su hermano Luisito, le produjo a Andrés “un gran estupor". ¿No sintió Andrés, o no quiso Baroja que sintiéramos con él? Tal vez ambas: porque sabemos, por notas biográficas en

${ }^{17}$ Ibid., p. 484.

${ }^{18} \mathrm{Ibid}$., p. 483-4. común, y por similares antipatías y simpatías filosóficas y políticas, que Baroja pensaba en él mismo cuando escribía de Andrés Hurtado. ¿Puede querer conmovernos un defensor acérrimo y radical de la ciencia, un partidario de la completa escisión de la mente y el cuerpo? ${ }^{19}$ Bajo esa concepción, la pasión, aun la intelectual, se encuentra anulada. ¿Pero qué es el pensamiento sin el ímpetu de pensar? La médula espinal, decía Sir Thomas Browne, no es más que cerebro prolongado. ${ }^{20}$ Pero -para hacer una metáfora anatómica-, los huesos de la novela de Baroja carecen de médula, o, como él diría, están "purificados"; son, de nuevo, una verdad muerta.

Ahora bien, no deja de ser curioso que esta verdad muerta se encuentre simbolizada en la novela, como ya apuntaba el título, con el árbol del conocimiento. En este sentido, y en contra de Kafka, para Baroja la desgracia de los hombres es no haber comido suficiente del árbol de la ciencia y desear el de la vida. Baroja está consciente de que, como dice Kafka, el conocimiento es, sin más, voluntad de eternidad; ${ }^{21}$ pero sostiene que lo eterno y lo vivo se excluyen inevitablemente. ${ }^{22}$ Si después de la

${ }^{19}$ Baroja, op. cit., p. 171.

${ }^{20}$ Sir Thomas Browne, "Pseudodoxia epidemica", op. cit., p. 17.

${ }^{21}$ Kafka, op. cit., p. 68.

${ }^{22}$ Para expresiones explícitas sobre esta oposición en la novela, véase sobre todo su cuarta 
Caída, Dios cercó con espadas de fuego el jardín del Edén y su localización se perdió para siempre en los mapas que nos es dado trazar, debemos renunciar absolutamente a la vida. "¿Qué se hace con la vida? -nos pregunta Andrés Hurtado¿Qué dirección se le da? Si la vida fuera [...]; pero la vida es estúpida". ${ }^{23}$ Podemos decir entonces, que la filosofía del personaje es menos una negación que una resignación por adelantado: no hay en ella ningún principio activo, ninguna gesticulación, salvo aquella que conducirá a la pasividad inamovible, al suicidio. Pero en Kafka se trata siempre de resistir, a pesar de todo, y más allá de lo imposible. Porque si el milagro de nuestra liberad se sitúa a caballo entre el tiempo y la eternidad, quizás pueda trascender también la sangrienta oposición entre el conocimiento y la vida. Finalmente, esa fe pertinaz, esa paciencia arrogante, están ya inscritas en la condición ambivalente de nuestra duración; y si, como dice Milton, el sabor del fruto que colgaba del árbol prohibido trajo la muerte al mundo, ${ }^{24}$ sólo

parte: Inquisiciones, donde se dice, por ejemplo: "Yo estoy convencido de que la verdad en bloque es mala para la vida. Esa anomalía de la naturaleza que se llama la vida necesita estar basada en el capricho, quizá en la mentira", op. cit., p. 166.

${ }^{23}$ Baroja, op. cit., p. 159.

24 "Of Man's first disobedience and the fruit / Of that forbidden tree whose mortal taste / Brought death into the world and all our woe / With loss of Eden till one greater Man / Restore us and regain the la trajo lentamente; pues, aunque el indefinido tósigo nos entrega a final unánime, inyecta también la fuerza para mirarlo a los ojos y dilatarlo. Porque todo lo de la vida es un a pesar de la muerte. ¡Anónimo, doble, discordante veneno! Reveló la desnudez de nuestros cuerpos y ocultó la extensión de nuestros días; acortó los goces del ocio, agudizó la resistencia a los trabajos.

No sólo estamos en pecado por haber comido del árbol del conocimiento, sino también por no haber comido aún del árbol de la vida. El simple trazo de este pensamiento parece el de una curva que se busca a sí misma, como si el relato de la Biblia hubiera esperado milenios para que Kafka, más descosiéndolo que comentándolo, completara su circunferencia en un anillo incorruptible. Un anillo en el que anverso y reverso están mostrándose simultáneamente, como una banda de Möbius, que por una paradójica magia del espacio, perpetúa la segunda dimensión en la tercera y se sustrae a las leyes del este y el otro lado. Este anillo es el lazo místico de la libertad, que todos los hombres llevamos en el dedo del corazón y que lleva sobre sí la doble significación de realización e impedimento, de pasión y atadura: aire y cristal; aldaba, zaguán.

blissful Seat, / Sing Heav'nly Muse", John Milton, Paradise Lost, 2005, Nueva York, Norton, ed. by Gordon Teskey, vv. 1-5. 